\title{
High Prevalence of Anal Oncogenic Human Papillomavirus Infection in Young Men Who Have Sex with Men Living in Bamako, Mali
}

Donato Koyalta ${ }^{1,2^{*}}$, Ralph-Sydney Mboumba Bouassa ${ }^{3,4}$, Almoustapha Issiaka Maiga ${ }^{5}$, Aliou Balde ${ }^{6}$ Jules Bashi Bagendabanga ${ }^{7}$, Almahdy Ag Alinity ${ }^{8}$, David Veyer ${ }^{4}$, Hélène Péré $^{4}$ and Laurent Bélec ${ }^{4}$

\begin{abstract}
Background: High-risk human papillomavirus (HR-HPV) anal infection is a major problem among men who have sex with men (MSM) living in sub-Saharan Africa. The prevalence of anal HR-HPV infection and associated risk factors were estimated in a cross-sectional study in MSM living in Bamako, Mali.

Methods: MSM consulting at sexual health center of the National NGO Soutoura, Bamako, were prospectively included. Sociodemographic and clinical-biological data were collected. HPV detection and genotyping were performed from anal swabs using multiplex real-time PCR. Risk factors associated with anal HPV infection were assessed by logistic regression analysis.

Results: Fifty MSM (mean age, 24.2 years; range, 18-35) of which $32.0 \%$ were infected with HIV-1, were prospectively included. The overall prevalence of anal HPV infection of any genotypes was $70.0 \%$ (35/50) with 80.0\% (28/35) of swabs positive for HR-HPV. HR-HPV-58 was the most detected genotype [13/35 (37.1\%)], followed by HRHPV-16 and low-risk (LR)-HPV-6 [12/35 (34.2\%)], LR-HPV-40 [10/35 (28.6\%)], LR-HPV-11 [9/35 (25.7\%)], HR-HPV-51 [8/ 35 (22.8\%)], HR-HPV types 18 and 39 [7/35 (20.0\%)] and LR-HPV-43 [6/35 (17.1\%)]. HR-HPV-52 and LR-HPV-44 were detected in lower proportions [5/35 (14.3\%) and 4/35 (11.4\%), respectively]. LR-HPV-42, LR-HPV-54, HR-HPV-31 and HR-HPV-35 were detected in very low proportions [3/35 (8.5\%)]. Multiple HR-HPV infections were diagnosed in onethird of anal samples [16/50 (32.0\%)], including around half of HR-HPV-positive anal swabs [16/35 (45.7\%)]. More than half [27/50 (54.0\%)] swabs were infected by at least one of HPV genotypes targeted by Gardasil-9 ${ }^{\oplus}$ vaccine, including a majority of vaccine HR-HPV [22/50 (44.0\%)]. In multivariate analysis, participation to sex in group was associated with anal infection by multiple HPV (aOR: 4.5, 95\% Cl: 1.1-18.1\%; $P=0.032$ ), and HIV-1 infection was associated with anal shedding of multiple HR-HPV (aOR: 5.5, 95\% Cl: 1.3-24.5\%; $P=0.024)$.
\end{abstract}

\footnotetext{
*Correspondence: koyaltad@yahoo.fr

${ }^{1}$ Centre Hospitalo-Universitaire Gabriel Touré, Bamako, Bamako, Mali

${ }^{2}$ Faculté des Sciences de la Santé Humaine de N'Djamena, N'Djamena, Chad

Full list of author information is available at the end of the article
}

(c) The Author(s). 2021, corrected publication 2021. Open Access This article is licensed under a Creative Commons Attribution 4.0 International License, which permits use, sharing, adaptation, distribution and reproduction in any medium or format, as long as you give appropriate credit to the original author(s) and the source, provide a link to the Creative Commons licence, and indicate if changes were made. The images or other third party material in this article are included in the article's Creative Commons licence, unless indicated otherwise in a credit line to the material. If material is not included in the article's Creative Commons licence and your intended use is not permitted by statutory regulation or exceeds the permitted use, you will need to obtain permission directly from the copyright holder. To view a copy of this licence, visit http://creativecommons.org/ licenses/by/4.0/. The Creative Commons Public Domain Dedication waiver (http://creativecommons.org/publicdomain/zero/1. 0/) applies to the data made available in this article, unless otherwise stated in a credit line to the data. 
Conclusions: These observations indicate that the MSM community living in Bamako is at high-risk for HR-HPV anal infections, with a unique epidemiological HPV genotypes profile and high prevalence of anal HPV covered by the Gardasil- $9^{\otimes}$ vaccine. Scaling up prevention strategies against HPV infection and related cancers adapted to this highly vulnerable MSM community should be urgently prioritized with innovative interventions.

Keywords: HPV, Anal, Molecular epidemiology, MSM, Prophylactic vaccine, Gardasil, Mali

\section{Introduction}

The human papillomavirus (HPV) is responsible for a significant disease burden in men who have sex with men (MSM), including benign and malignant lesions [1]. Anogenital warts, cancers of the penis, anus and oropharynx represent a relevant health problem in MSM populations worldwide [1]. Overall, oncogenic high-risk (HR)-HPV genotypes are responsible for the majority of anal cancers $[2,3]$.

In sub-Saharan Africa, the MSM populations have been identified as core groups for several sexually transmitted infections (STIs), including human immunodeficiency virus (HIV) $[4,5]$, herpes simplex virus 2 , and HPV [6, 7]. The burden of HPV infection among MSM living in sub-Saharan Africa, although nonetheless poorly documented, is important [7]. Thus, the reported prevalences of anal HR-HPV infection among MSM living in sub-Saharan Africa appear to be higher than those usually recorded in studies conducted in developed countries, which range from $20.9 \%$ to $65 \%$ [8, 9]. Recent reports from South Africa [10] and Nigeria [11] highlight very high prevalence of anal HR-HPV infection, ranging from $57.6 \%$ to $70.1 \%$, among MSM living in sub-Saharan Africa, particularly among those co-infected with HIV $[10,11]$. Anal HR-HPV infection in African MSM was strongly associated with high-risk sexual behaviors such as having sex with men only, participating to group sex, and having receptive anal sex without a condom [10, 11]. Interestingly, a great diversity of predominant HPV genotypes has been observed in South African and Nigerian studies, suggesting the possibility of unique spatial distributions of HPV diversity by region in subSaharan Africa [10, 11]. Müller and colleagues described in South Africa a distribution quite similar to that commonly observed in the world with HPV-16 as the predominant genotype [10]. In contrast, Nowak and colleagues depicted an atypical distribution profile in Nigeria with non-vaccine HR-HPV-35 as the predominant genotype circulating in MSM [11]. Although limited, these observations highlight that MSM in sub-Saharan Africa constitute a central group at high-risk for HPV infections and that the distribution of the main HPV genotypes involved in anal cancers in African MSM may be quite different from that generally observed. Finally, in order to implement effective prevention based on prophylactic HPV vaccine adapted to each region of
sub-Saharan Africa, it is important to establish the molecular distribution of the predominant genotypes of HR-HPV circulating in African MSM.

High prevalences of anal HR-HPV infections in MSM living in West Africa, including Burkina Faso [12], Liberia [13], Mali [12], Nigeria [11, 14], Togo [15], and Senegal [16], have been reported. Since the epidemiological situation of HPV infection in MSM may be specific in a given area [7], with implication on prophylactic HPV vaccine efficacy, we herein designed a crosssectional study to assess the prevalence and genotypes distribution of anal HPV and associated risk factors, including sexual behavior, in a population of HIV-infected and non-HIV-infected MSM living in Bamako, the capital of Mali.

\section{Material and Methods}

Study Population, Medical Interventions, and Data Collection The Clinic of the National NGO Soutoura, Bamako, Mali is a specialized care center exclusively dedicated to key populations. It offers counseling, testing, care, and support to MSM from Bamako. MSM regularly attend the center for HIV and STI screening and care, to receive specific treatment, HIV counseling and HIV global support for those tested positive. For purposes of the study, a specific strategy involving peer educators was adopted in order to confirm the accuracy of homosexuality of the included MSM. Thus, inclusion criteria were to be in majority age (age $\geq 18$ years), to be approved as having sex with men by his peers, to get possible follow up for at least 3 months, to have a fully informed medical and socio-demographic record, and to sign the informed consent form. Refusal to participate and age under 18 were set as exclusion criteria.

At inclusion, a standardized interview was conducted to collect socio-demographic characteristics and behavioral data, including age, number of male sexual partners in the past 6 months, sexual orientation, frequency of condom use, sexual practices, HIV status and antiretroviral treatment for those who were already aware of their positive HIV status and finally to advise participants on HIV and associated STIs.

After the interviews, MSM undertook medical appointments including clinical examinations and biological investigations for the diagnosis of the most 
common STIs including HIV (for those who did not know their HIV-serological status), syphilis and hepatitis B. Biological results were returned 72 hours after and those positive for STIs received adapted treatment. HIVpositive MSM were enrolled in the HIV cohort followed in the center. The medical intervention package consisted of HIV/STI counseling, condom distribution, clinical examination, biological monitoring, and medical care for patients infected with STIs and HIV. A medical professional carried out physical and clinical examinations to check patients for symptoms of potential diseases. For HIV/STI counseling and condom distribution, a 7 to 10-minute interactive conversation on HIV, STIs, their modes of transmission and effective prevention mean with a special emphasis on condom use as an easy and effective prevention tool, was carried out by health care assistants. At the end, the health care assistants distributed as many condoms as required to the participants.

Samples and Processing Plasma or serum samples from blood collected by venipuncture in each MSM have been used for serological testing for HIV infection, as recommended by the national algorithm of the Mali HIV National Control Program, using in series OnSite HIV1/2 Ab Plus Combo Rapid Test (CTK Biotech Inc., Poway, Ca, USA) for HIV screening and ImmunoComb ${ }^{\circ}$ II HIV 1\&2 BiSpot (Orgenics Ltd., Yavne, Israël) for confirmation [17]. Samples for HPV molecular testing and genotyping were obtained by inserting a wet cotton swab into the anal canal, rotating 5 times and then removing. The swab was immediately placed in a sample tube then put in a cooler containing frozen ice packs, and finally frozen at $-80^{\circ} \mathrm{C}$ within 1 hour. Frozen swabs were further send in ice in the Laboratoire de Virologie, hôspital Européen Georges Pompidou, Paris, France, for HPV detection and genotyping. All samples were kept frozen at $-80^{\circ} \mathrm{C}$ before the DNA extraction procedure.

HPV Detection and Genotyping DNA was extracted from the anal swab sample using the DNeasyBlood and Tissue kit, as recommended by the manufacturer (Qiagen, Hilden, Germany). HPV DNA detection and genotype distribution were performed using the Anyplex ${ }^{\mathrm{Tm}}$ II HPV28 detection assay (Seegene, Seoul, South Korea), as previously described [18]. The Anyplex ${ }^{\mathrm{mat}}$ II HPV28 detection test distinguishes 28 genotypes of HPV, including 13 high-risk types (HR-HPV -16, -18, -31, -33, -35, -39, $-45,-51,-52,-56,-58,-59$ and -68$), 9$ low-risk types (LR) (LR-HPV -6, - $11,-40,-42,-43,-44,-53,-54$ and $-70)$, then 6 genotypes reported as possibly carcinogenic (HPV-26, -61, -66, -69, -73 and -82).
Statistical Analyzes Statistical analyzes were performed using SAS 9.4 (SAS Institute Inc., NC, USA). $P$ values were calculated using Fisher's exact test for categorical variables and using Mann-Whitney $U$-test for quantitative variables. Logistic regression models were assessed to evaluate the association of each independent variable [i.e., age at enrollment, HIV-1 infection, sex of sexual partner (MSM-exclusively or MSMW), the number of sexual male partners in the last 6 months, and sexual practices in the last 6 months (condomless receptive anal sex; condomless insertive anal sex; regular receptive oral sex)] with the HPV type-specific anal infections (i.e., anal infection by any type of HPV, multiple types of HPV, HR-HPV and multiple HR-HPV). All variables statistically significant $(P<0.05)$ in univariate analyses were entered into multivariate logistic regression models. Crude Odds ratio (cOR) and adjusted Odds ratio (aOR) were calculated, as appropriate along with $95 \%$ confidence intervals $(\mathrm{CI})$. For variable giving infinite OR, the Odds ratios and their confidence intervals were recalculated, using the statistical software package $\mathrm{R}$ (available at https://www.r-project.org/) and the hypothesis test inversion method, as previously described [19]. The final multivariate model for any HPV outcome included condomless receptive and insertive anal sex and regular receptive oral sex. For multiple HPV outcome, the final multivariate model included condomless receptive and insertive anal sex and regular receptive oral sex. For HRHPV outcomes, the final multivariate model included condomless insertive anal sex and regular receptive oral sex. Finally, for the multiple HR-HPV outcomes variable, the final multivariate model included HIV infection and condomless insertive anal sex.

Ethics Statement The approval of the study was obtained from the Scientific Committee of the University of Bamako, Mali, which constitutes the national Ethics Committee. All participating MSMs were of legal age and their informed consent was obtained before each questionnaire was documented.

\section{Results}

Characteristics of Study Population Fifty participants were included from April to September 2019 and their socio-demographic, sexual, clinical and biological characteristics are presented in Table 1. Among them, 16 (32.0\%) were infected with HIV-1 and 34 (68.0\%) were HIV-negative. The majority of HIV-positive participants were yet followed up at Clinic of the National NGO Soutoura $(90.0 \%)$ and took highly active antiretroviral therapy (87.5\%).

Study MSM were exclusively Malian, and mainly young men (mean age, 24 years; range, 18-35). HIV- 
Table 1 Baseline characteristics according to sexual behavior and HIV serostatus among the 50 study men who have sex with men (MSM) living in Bamako, Mali

\begin{tabular}{|c|c|c|c|c|c|c|c|}
\hline Characteristics & Overall & MSM-exclusively & MSMW & $P^{*}$ & HIV- & HIV+ & $P^{*}$ \\
\hline Number & 50 & 38 & 12 & & 34 & 16 & \\
\hline $\begin{array}{l}\text { Age }[\text { mean }(\mathrm{SD}), \text { years }] \\
<20 \\
20-29 \\
\geq 30\end{array}$ & $\begin{array}{l}24(4.8) \\
12(24.0) \\
30(60.0) \\
8(16.0)\end{array}$ & $\begin{array}{l}24(4.7) \\
10(26.3) \\
23(60.5) \\
5(13.2)\end{array}$ & $\begin{array}{l}26(5.2) \\
2(16.7) \\
7(58.3) \\
3(25.0)\end{array}$ & 0.244 & $\begin{array}{l}23(4.5) \\
11(32.4) \\
20(58.8) \\
3(8.8)\end{array}$ & $\begin{array}{l}27(5.0) \\
1(6.2) \\
10(62.5) \\
5(31.3)\end{array}$ & 0.018 \\
\hline $\begin{array}{l}\text { Age at first intercourse [mean (SD), years] } \\
<15 \\
15-17 \\
\geq 18\end{array}$ & $\begin{array}{l}16(2.2) \\
7(14.0) \\
24(48.0) \\
19(38.0)\end{array}$ & $\begin{array}{l}16(2.2) \\
6(15.8) \\
18(47.4) \\
14(36.8)\end{array}$ & $\begin{array}{l}17(2.2) \\
1(8.3) \\
6(50.0) \\
5(41.7)\end{array}$ & 0.200 & $\begin{array}{l}17(2.2) \\
4(11.8) \\
17(50.0) \\
13(38.2)\end{array}$ & $\begin{array}{l}16(2.3) \\
3(18.7) \\
7(43.8) \\
6(37.3)\end{array}$ & 0.519 \\
\hline $\begin{array}{l}\text { HIV infection [n (\%)] } \\
\text { CD4 T cell count [median (range), cells/ } / \mathrm{L}] \\
\text { Under HAART [n (\%)] }\end{array}$ & $\begin{array}{l}16(32.0) \\
570(327-978) \\
14(87.5)\end{array}$ & $\begin{array}{l}12(31.6) \\
541(327-842) \\
10(83.3)\end{array}$ & $\begin{array}{l}4(33.3) \\
645(469-978) \\
4(100.0)\end{array}$ & 0.995 & NA & NA & \\
\hline $\begin{array}{l}\text { Family situation [n (\%)] } \\
\text { Single } \\
\text { Couple }\end{array}$ & $\begin{array}{l}38(76.0) \\
12(24.0)\end{array}$ & NA & NA & NA & $\begin{array}{l}26(76.5) \\
8(23.5)\end{array}$ & $\begin{array}{l}12(75.0) \\
4(25.0)\end{array}$ & 0.999 \\
\hline $\begin{array}{l}\text { Number of sexual partners in last } 6 \text { months [n (\%)] } \\
1-5 \\
>5\end{array}$ & $\begin{array}{l}40(80.0) \\
10(20.0)\end{array}$ & $\begin{array}{l}28(73.7) \\
10(26.3)\end{array}$ & $\begin{array}{l}12(100.0) \\
0(0.0)\end{array}$ & 0.092 & $\begin{array}{l}27(79.4) \\
7(20.6)\end{array}$ & $\begin{array}{l}13(81.3) \\
3(18.7)\end{array}$ & 1.0 \\
\hline $\begin{array}{l}\text { Use of condom [n (\%)] } \\
\text { Never } \\
\text { Sometimes } \\
\text { Always }\end{array}$ & $\begin{array}{l}3(6.0) \\
46(82.0) \\
1(2.0)\end{array}$ & $\begin{array}{l}1(2.5) \\
36(94.5) \\
1(2.5)\end{array}$ & $\begin{array}{l}2(16.7) \\
10(83.3) \\
0(0.0)\end{array}$ & 0.768 & $\begin{array}{l}2(5.9) \\
31(91.2) \\
1(2.9)\end{array}$ & $\begin{array}{l}1(6.2) \\
15(93.8) \\
0(0.0)\end{array}$ & 0.876 \\
\hline Engaged in group sex [n (\%)] & $18(36.0)$ & $15(39.5)$ & $3(25.0)$ & 0.497 & $11(32.4)$ & $7(43.7)$ & 0.532 \\
\hline Practicing ChemSex [n (\%)] & $12(24.0)$ & $12(31.6)$ & $0(0.0)$ & 0.046 & $8(23.5)$ & $4(25.0)$ & 1.0 \\
\hline Receptive anal intercourse [n (\%)] & $40(80.0)$ & $31(81.6)$ & $9(75.0)$ & 0.685 & $25(73.5)$ & $15(93.8)$ & 0.094 \\
\hline Insertive anal intercourse [n (\%)] & $34(68.0)$ & $25(65.8)$ & $9(75.0)$ & 0.727 & $21(61.8)$ & $13(81.3)$ & 0.208 \\
\hline Receptive oral sex [n (\%)] & $36(72.0)$ & $26(68.4)$ & $10(83.3)$ & 0.468 & $22(64.7)$ & $14(87.5)$ & 0.175 \\
\hline Insertive oral sex [n (\%)] & $43(86.0)$ & $33(86.8)$ & $10(83.3)$ & 0.789 & $27(79.4)$ & $16(100.0)$ & 0.081 \\
\hline STI gonorrhea [n (\%)] & $20(40.0)$ & $17(44.7)$ & $3(25.0)$ & 0.316 & $12(35.3)$ & $8(50.0)$ & 0.366 \\
\hline STI Chlamydia [n (\%)] & $7(14.0)$ & $7(18.4)$ & $0(0.0)$ & 0.174 & $4(11.8)$ & $3(18.7)$ & 0.665 \\
\hline
\end{tabular}

* $P$-value calculated using Pearson's X2 test or Fisher's exact test for categorical variables and the non-parametric Mann-Whitney $U$-test for non-categorical variables

HAART Highly active antiretroviral therapy, MSM men who have sex with men, MSM-exclusively men who have sex only with men, MSMW men who have sex with both men and women, NA Not applicable, NS Not significant

infected MSM were older than HIV-negative MSM. The average age of participants for the first sexual intercourse was 16-year-old. The majority of participants [38/50 (76\%)] reported being single, while a minority $[12 / 50(24 \%)]$ were in a relationship. Most [40/50 (80\%)] of MSM reported having had sex with at least 1 to 5 partners in the past 6 months and most of them [46/50 (82\%)] used only sometimes condoms during sex. The prevalence of STIs was high in study population. Sexual practices were not significantly different between exclusive MSM and men having sex with both men and women (MSMW). HIV-infected MSM reported practicing receptive oral sex more frequently than HIVnegative MSM [14/16 (87.5\%) versus 22/34 (64.7\%)], however without statistical differences.

HPV Prevalence and Genotypes Distribution As shown in Table 2 and Fig. 1, the overall prevalence of anal HPV infection of any genotypes in the study population was $70.0 \%(35 / 50)$ with $80.0 \%(28 / 35)$ of samples positive for HR-HPV DNA. Most [28/50 (56.0\%)] of the anal swabs contained multiple HPV genotypes and $57.1 \%(16 / 28)$ of them contained an average of $3.7 \mathrm{HR}$ HPV per anal swab specimen. The majority $[28 / 35$ (80.0\%)] of HPV-positive samples showed at least $1 \mathrm{HR}$ HPV.

HR-HPV-58 was the most detected genotype [13/35 (37.1\%)], followed by HR-HPV-16 and LR-HPV-6 [12/35 (34.2\%)], LR-HPV-40 [10/35 (28.6\%)], LR-HPV-11 [9/35 (25.7\%)], HR-HPV-51 [8/35 (22.8\%)], HR-HPV types 18 and 39 [7/35 (20.0\%)] and LR-HPV-43 [6/35 (17.1\%)]. HR-HPV-52 and LR-HPV-44 were detected in lower proportions $[5 / 35(14.3 \%)$ and $4 / 35$ (11.4\%), respectively]. LR-HPV-42, LR-HPV-54, HR-HPV-31 and HRHPV-35 were detected in very low proportions [3/35 (8.5\%)] (Fig. 1). Multiple HR-HPV infections were 
Table 2 HPV test results according to sexual behavior and HIV serostatus among the 50 study men who have sex with men (MSM) living in Bamako, Mali

\begin{tabular}{|c|c|c|c|c|c|c|c|}
\hline Characteristics & Overall & MSM-exclusively & MSMW & $P^{*}$ & HIV- & HIV+ & $P^{*}$ \\
\hline Number & 50 & 38 & 12 & & 34 & 16 & \\
\hline Any anal HPV [n (\%)] & $35(70.0)$ & $25(65.8)$ & $10(83.3)$ & 0.304 & $21(61.8)$ & $14(87.5)$ & 0.098 \\
\hline Multiple anal HPV [n (\%)] & $28(56.0)$ & $21(55.3)$ & $7(58.3)$ & 1.0 & $15(44.1)$ & $13(81.3)$ & 0.016 \\
\hline Anal HR-HPV [n (\%)] & $28(56.0)$ & $21(55.3)$ & $7(58.3)$ & 1.0 & $16(47.1)$ & $12(75.0)$ & 0.076 \\
\hline Multiple HR-HPV [n (\%)] & $16(32.0)$ & $12(31.6)$ & $4(33.3)$ & 1.0 & $7(20.6)$ & $9(56.3)$ & 0.021 \\
\hline HPV-16 [n (\%)] & $12(24.0)$ & $6(15.7)$ & $6(50.0)$ & 0.704 & $5(14.7)$ & $7(43.7)$ & 0.036 \\
\hline HPV-18 [n (\%)] & $7(14.0)$ & $4(10.5)$ & $3(25.0)$ & 0.336 & $4(11.8)$ & $3(18.7)$ & 0.665 \\
\hline HPV-16 and HPV-18 [n (\%)] & $4(8.0)$ & $2(5.2)$ & $2(16.7)$ & 0.239 & $2(5.9)$ & $2(12.5)$ & 0.584 \\
\hline Any 4-valent vaccine HPV [n (\%)] $]^{\mu}$ & $24(48.0)$ & $17(44.7)$ & $7(58.3)$ & 1.0 & $14(41.2)$ & $10(62.5)$ & 0.574 \\
\hline Multiple 4-valent vaccine HPV [n (\%)] & $12(24.0)$ & $8(21.0)$ & $4(33.3)$ & 0.876 & $6(17.6)$ & $6(37.5)$ & 0.658 \\
\hline Any 9-valent vaccine HPV [n (\%)] $]^{\varepsilon}$ & $27(54.0)$ & $18(47.4)$ & $9(75.0)$ & 0.321 & $16(47.0)$ & $11(68.7)$ & 0.256 \\
\hline Multiple 9-valent vaccine HPV [n (\%)] & $21(42.0)$ & $14(36.8)$ & $7(58.3)$ & 0.379 & $12(35.3)$ & $9(56.2)$ & 0.30 \\
\hline Any 4-valent vaccine HR-HPV [n (\%) $]^{\mu}$ & $15(30.0)$ & $12(31.6)$ & $3(25.0)$ & 0.899 & $8(23.5)$ & $7(43.7)$ & 0.125 \\
\hline Multiple 4-valent vaccine HR-HPV [n (\%)] & $8(16.0)$ & $6(15.8)$ & $2(16.7)$ & 1.0 & $5(14.7)$ & $3(18.7)$ & 0.573 \\
\hline Any 9-valent vaccine HR-HPV [n (\%) $]^{£}$ & $22(44.0)$ & $15(39.4)$ & $7(58.3)$ & 0.954 & $13(38.2)$ & $9(56.2)$ & 0.206 \\
\hline Multiple 9-valent vaccine HR-HPV [n (\%)] & $16(32.0)$ & $12(31.6)$ & $4(33.3)$ & 1.0 & $10(29.4)$ & $6(37.5)$ & 0.67 \\
\hline
\end{tabular}

${ }^{*} P$-value calculated using Pearson's X2 test or Fisher's exact test for categorical variables and the non-parametric Mann-Whitney $U$-test for non-categorical variables

${ }^{\mu}$ The 4-valent Gardasil- $4^{\oplus}$ vaccine (Merck \& Co. Inc., New Jersey, USA) is effective against HPV genotypes $6,11,16$ and 18

${ }^{ \pm}$The 9-valent Gardasil-9 ${ }^{\circledR}$ vaccine is effective against HPV genotypes 6, 11, 16, 18, 31, 33, 45, 52 and 58

HR-HPV high-risk human papillomavirus, LR-HPV low risk human papillomavirus, MSM men who have sex with men, MSM-exclusively men who have sex only with men, MSMW men who have sex with both men and women, NS Not significant

diagnosed in one-third of anal samples [16/50 (32.0\%)], including around half of HR-HPV-positive anal swabs [16/35 (45.7\%)]. HPV-16 and/or HPV-18 were detected in around one-third $[15 / 50(30.0 \%)]$ of anal samples, including a minority [4/50 (8.0\%)] infected with both HPV-16 and HPV-18. HPV-16 and HPV-18 were found in less than half $[15 / 35(42.8 \%)]$ anal samples positive for HR-HPV.
Of the 14 HIV-1-infected MSM with anal HPV, the quasi-totality [13/14 81.3\%)] had multiple HPV infection and $2(16.7 \%)$ were coinfected with HR-HPV types 16 and 18 (Table 2). HIV-infected MSM showed significantly more frequent multiple anal HPV, multiple anal HR-HPV genotypes and HPV-16 infection than HIVnegative MSM (multiple HPV: $81.3 \%$ versus $44.1 \%, P=$ 0.0168; multiple HR-HPV: $56.3 \%$ versus $20.6 \%, P=$

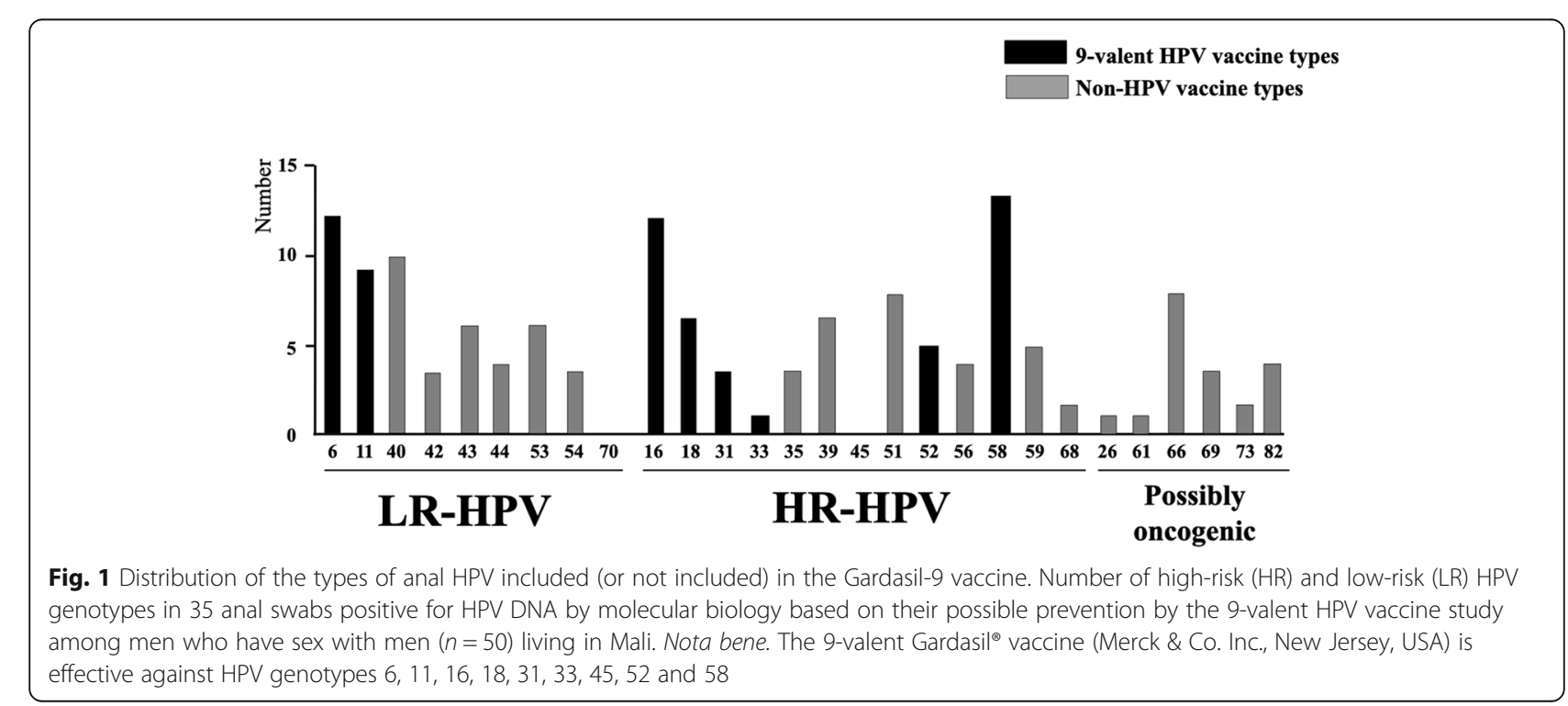


0.0214; HPV-16: $43.7 \%$ versus $14.7 \%, P=0.0363)$. MSMexclusively were less infected with anal HPV [25/38 $(65.8 \%)]$ than bisexual MSM [10/12 (83.3\%)], but the difference was not significant.

Possible efficiencies of anal HPV prevention by 4- and 9- valent Gardasil ${ }^{\circ}$ vaccines were further assessed (Table 2 and Fig. 1). Around half [24/50 (48.0\%)] anal samples were infected by at least one HPV genotypes targeted by the Gardasil- $4^{\circ}$ vaccine, and around one-third [15/50 (30.0\%)] of HPV-positive anal samples harbored at least 1 HR-HPV 4-valent Gardasil ${ }^{\circ}$ genotype. Anal HPV genotypes targeted by the 9 -valent prophylactic Gardasil- $9^{\circ}$ vaccine were more frequent than those targeted by Gardasil- $4^{\circ}$ vaccine, with a little more than half [27/50 $(54.0 \%)]$ anal samples, including a majority of vaccine HR-HPV [22/50 (44.0\%)]. Among 9-valent Gardasil ${ }^{\circ}$ vaccines genotypes, HPV-58 was the most detected in the study population $[13 / 35$ (37.1\%)], followed by HPV-16 [12/35 (34.3\%)], -18 [7/35 (20.0\%)], -52 [5/35 (14.2\%)], $-31[3 / 35(8.6 \%)]$ and -33 [1/35 (2.8\%)] (Fig. 1). More than half $(53.6 \% ; 15 / 28)$ of anal HR-HPV infections would be prevented by Gardasil- $4^{\circ}$ vaccine and more than three-quarters $(78.6 \% ; 22 / 28)$ by the Gardasil- $9^{\circ}$ vaccine.

HIV-infected MSM were found to be significantly more infected with HPV and HR-HPV genotypes targeted by 4 - and 9- valent Gardasil ${ }^{\circ}$ vaccines than HIVnegative MSM, although the differences did not reach significance (Table 2 and Fig. 2).

Risk Factors Associated with Anal HPV Shedding The associations between anal HPV infection, including anal infection by any type of HPV, multiple types of HPV, HR-HPV type and multiple types HR-HPV, with their potential risk factors were assessed by logistic regression analysis, as shown in Table 3.

In the univariate analysis, anal infection by any HPV was significantly associated with the practice of condomless receptive anal sex (cOR: 5.2, 95\% CI: 1.3-20.3\%; $P=$ 0.018 ) and receptive oral sex (cOR: $3.5,95 \%$ CI: $1.1-$ $11.5 \% ; P=0.038$ ) and HIV-infection (cOR: $4.3,95 \% \mathrm{CI}$ : 1.2-15.2\%; $P=0.022$ ); anal infection with multiple HPV as well as anal infection with HR-HPV genotypes were both associated with HIV infection (cOR: 5.5, 95\%CI: 1.8-16.8\%; $P=0.002$ and cOR: 3.4, 95\% CI: $1.2-9.6 \%$; $\mathrm{P}=0.022$, respectively) and the practice of group sex (cOR: 4.5, 95\% CI: $1.6-12.9 \% ; P=0.005$ and cOR:3.0, 95\% CI: $1.1-8.1 \% ; P=0.035$, respectively); finally anal infection with multiple HR-HPV was associated with HIV infection (cOR: 5.0, 95\% CI: 1.7-14.7\%; $P=0.003$ ).

In the multivariate analysis, only being infected with HIV and having participated in group sex party remained significantly linked to anal infection with multiple HPV infection (aOR: 5.5, 95\% CI: $1.3-24.5 \%$; $P=$ 0.024 and aOR: $4.5,95 \%$ CI: $1.1-18.1 \%$; $P=0.032$ ).

\section{Discussion}

The present study assessing the epidemiological features of anal HPV infection within the MSM community living in Mali, followed up at the main care center exclusively dedicated to HIV key populations in Bamako, the Clinic of the National NGO Soutoura, showed remarkable findings. Firstly, the prevalence of anal HPV was also particularly high $(70.0 \%)$ and unique due to the high prevalence of HR-HPV (80.0\%), high genotypes diversity and frequent (45.7\%) multiple HR-HPV infections among HPV-positive samples. Secondly, the distribution of anal HPV appeared specific to study population, the

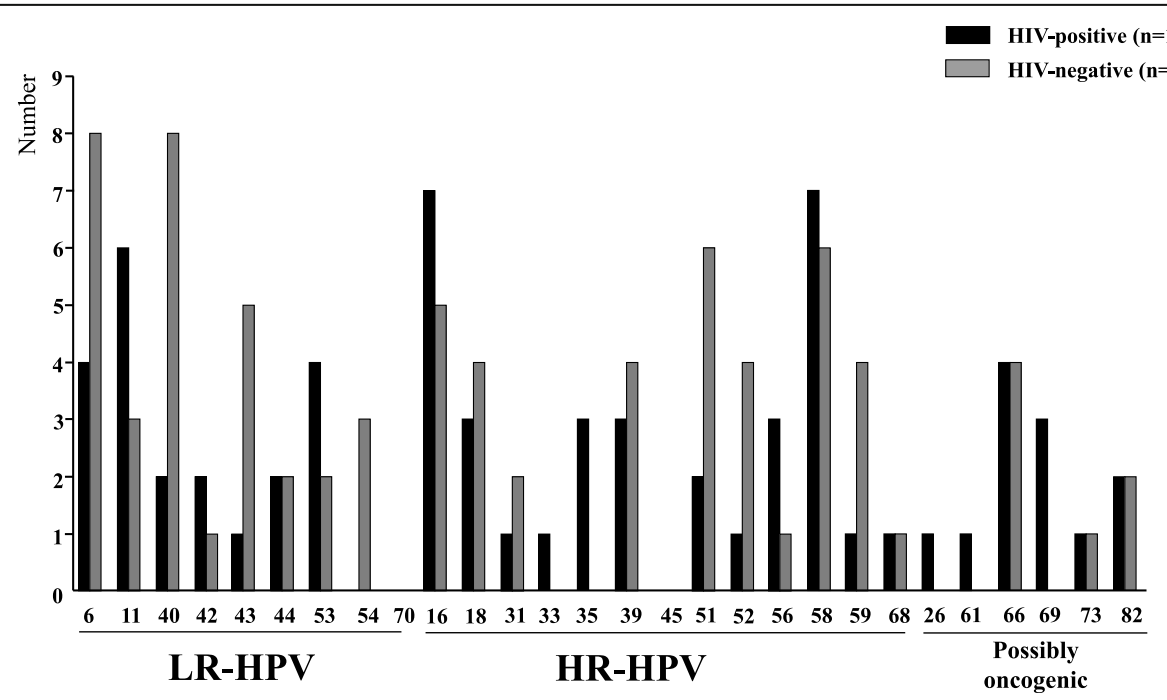

Fig. 2 Distribution of anal HPV types according to the HIV-serostatus. Number of high-risk (HR) and low-risk (LR) HPV genotypes in anal swab positive for HPV DNA by molecular biology according to HIV-serostatus among study men who have sex with men ( $n=50)$ living in Bamako, Mali 


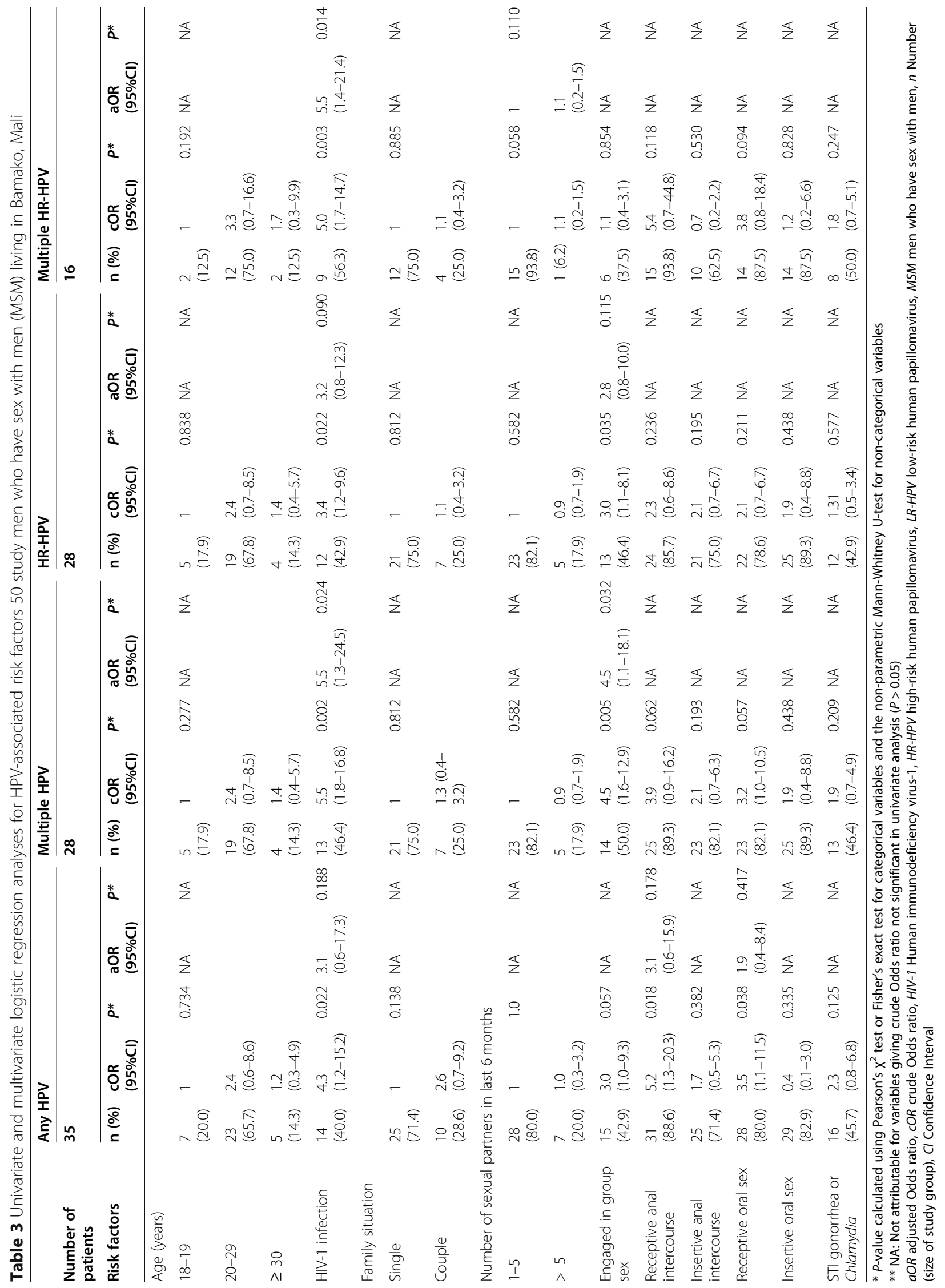


most prevalent genotypes being HR-HPV-58, followed by HPV-6, HPV-16, HPV-40, HPV-11, HPV-51, HPV-18 and HPV-39, while HPV-43, HPV-52 and HPV-44 were in lower proportions, and HPV-42, HPV-54, HPV-31 and HPV-35 in very low proportion. The classical HRHPV-16 and HR-HPV-18 were only present in less than half (42.8\%) of HR-HPV-positive anal samples, likely indicating possible regional clusterization in the diffusion of certain HR-HPV genotypes within the MSM community living in Bamako. Thirdly, all HPV types targeted by the prophylactic Gardasil- $9^{\circ}$ vaccine, except HPV-45, were detected in the majority (78.6\%) of HR-HPVpositive anal samples, suggesting that the current 9valent vaccine could be beneficial for the prevention of HPV-associated disease in the majority of MSM community living in Bamako, although around one-fifth of HPV anal infection would not be prevented. Finally, the practice of sex group was significantly associated with infection by multiple anal HPV, and HIV infection with the anal carriage of HR-HPV. Taken together, our observations indicate for the first time that the MSM community living in Bamako should be at very high-risk for HR-HPV anal infections, and strongly suggest that scaling up prevention strategies against HPV infection and related cancers adapted to this highly vulnerable MSM community should be urgently prioritized with innovative interventions.

The prevalence of HIV-1 infection in study MSM was notably high $(32.0 \%)$ compared to the national HIV prevalence in Mali, which is $1.1 \%$ [20]. HIV prevalence among MSM in Bamako was estimated in 2015 at 13.7\% using respondent driven sampling on a large cohort of 552 MSM, eight times the prevalence among men in general population from the same city [21, 22]. The HIV prevalence found in our study was more than twice higher, probably linked to a recruitment bias, since the Clinic of the National NGO Soutoura preferentially deals with key populations in relation to the HIV risk.

The prevalence of anal HPV was particularly high in this sample of MSM from the Bamako's community. The high prevalence of anal HR-HPV in our study MSM appeared quite similar to the prevalence reported in MSM living in Liberia, Togo, South Africa, Central African Republic and Nigeria, ranging from $45 \%$ to $72 \%$ $[10-13,15,18]$, but lower than the prevalence reported in young Black American MSM (87\%) [23]. Other reports conducted outside Africa showed relatively high anal HR-HPV prevalence rates, ranging from $29 \%$ to 56\% [24-27]. Overall, anal HR-HPV infection was up to 4-10 times more frequent in MSM living in many countries outside Africa than in heterosexual men [28, 29]. Finally, our observations confirm that anal HPV constitutes a major infectious health concern in the MSM living in Bamako, highly escalated by HIV infection, and that each MSM community is characterized by local epidemiological specificities rendering necessary their epidemiological characterization before the implementation of any intervention.

In our series, the distribution of anal HPV in anal samples appeared specific and unique, with a mixture of HR-HPV and LR-HPV. Among HR-HPV, HPV-58 (37.1\%) was the predominant genotype, followed by HPV-16 with a very close prevalence $(34.2 \%)$, and HPV -51 (22.8\%), HPV -18 and -39 (20.0\%). This distribution partly mirrors the previous observations by Nowak and colleagues, reporting that anal samples from MSM living in Nigeria harbored HPV-58 as the most prevalent 9 -valent vaccine genotype followed by HPV-16 and HPV-18 as minor genotypes [11]. Similarly, in the Central African Republic, Mboumba Bouassa and colleagues reported in MSM living in Bangui that the most prevalent 9-valent vaccine $H R$ HPV was HPV-58, while HPV-16 and HPV-18 were very poorly represented [18]. Study MSM in Bamako harbored however a very low prevalence of HPV-35 (8.5\%), which was in contrast highly represented in the Central African Republic [18] and Nigeria [11, 14]. Finally, the anal HR-HPV distribution in study MSM living in Bamako appeared intermediate between the most frequent genotypes distribution usually observed in Western countries and South Africa, and some unique distribution of rare genotypes reported in some sub-Saharan African countries. Thus, HR-HPV distribution in our MSM series showed relatively high prevalence of HR-HPV-58 as previously reported in sub-Saharan Africa $[11,14,18]$ in association with relatively high frequency of HPV-16 as previously reported in MSM living in South Africa [10], and with low frequency of poorly encountered genotypes such as HPV-35 which is thought to be clusterized in certain African MSM population in sub-Saharan Africa [11, 14, 18]. Taken together, these observations suggest the possibility of a regional distribution in molecular epidemiology of HR-HPV within the diverse MSM communities inside the subSaharan African continent [7]. Thus, it is possible to hypothesize that anal cancers in certain black African MSM populations may be due to other HR-HPV rather than HPV-16 and HPV-18, which constitute the most frequently HR-HPV types involved in anal cancers in MSM living in Western countries $[30,31]$. In Mali, there is no data on the HPV type specific prevalence in the general population. It would be interesting to check whether the particular HPV genotype distribution found in our Malian MSM series is similar to that in the female or general population. Further studies are nevertheless needed to determine the natural history and the burden of HPV-associated 
diseases in black African MSM in order to confirm our observations and to formulate effective and adapted HPV vaccine strategies towards young African MSM.

The coverage offered by the Gardasil- $9^{\circ}$ vaccine in study MSM was much higher than that given by the Gardasil- $4^{\circ}$ vaccine. Thus, HPV types targeted by the prophylactic Gardasil-9 $9^{\circ}$ vaccine were detected in more than half (54.0\%) of HPV-positive anal samples. All types of HPV targeted by the Gardasil- $9^{\circ}$ vaccine were detected in the majority (78.6\%) of HR-HPV-positive anal samples, except the HPV-45 which was not detected, and $42 \%$ of HPV-positive anal specimens contained multiple 9-valent HPV vaccine types. Similarly, high rates of 9-valent HPV vaccine types in anal canal of MSM were previously reported in South Africa (57\%) [10] and Central African Republic (68.9\%) [18]. These observations indicate that MSM living in Bamako, as other MSM populations, constitute a key target population for HPV vaccination with the current prophylactic Gardasil-9 ${ }^{\circ}$ vaccine, which would potentially prevent most of HPV infections and associated anal diseases. However, anal HR-HPV not included in the prophylactic 9-valent vaccine, including HPV-39, HPV-51 and HPV-35, were found in one-fifth (21.4\%) of study MSM, indicating that the current HPV vaccine may be insufficient to prevent HPV-related diseases in a significant proportion of the MSM community living in Mali. Thus, the guidelines on HPV immunization recommended in 2015 by the American Cancer Society (ACS), which integrate HPV vaccination up to 26 years for young MSM with the current two large spectrum HPV vaccines [32, 33], because HPV-16 and HPV-18 are mostly involved in HPVassociated anal cancer in Western countries [30, 31], may be only partially adapted to the MSM community living in Mali and other sub-Saharan African settings.

Among various evaluated risk factors, participation to sex group was associated with anal infection by multiple HPV, and HIV infection was associated with anal shedding of multiple HR-HPV, after adjusting for confounders and other variables found significant in the univariate analysis. The other possible associations did not reach statistical differences. Thus, the population of study HIV-positive MSM living in Bamako constituted a high-risk group accumulating several risky sexual behaviors and multiple anal HR-HPV infections.

Sex group was associated with higher risk of anal HPV shedding in study MSM. This finding is reminiscent with the increased sexual disinhibition among MSM community in Cape Town, South Africa, in whom being engaged in group sex in lifetime was associated with 4.7-fold-risk having any anal HPV infection and 3.1-fold-risk of having a greater likelihood of anal infection by a HR-HPV type [10]. Furthermore, study MSM only used condoms inconsistently. These findings confirm that the risk of anal HPV acquisition is strongly associated with high-risk sexual behavior in the MSM population. Indeed, MSM practicing condomless anal intercourse with male partners are more likely to acquire HIV, various STIs and anal HPV than those who only practice condomless insertive anal intercourse, with exacerbation in direct relationship to the number of sexual partners [34].

Multiple HR-HPV were frequently detected in anal swabs from Bamako's MSM, mainly in HIV-infected individuals. Multiple anal HR-HPV infection in MSM living in sub-Saharan Africa was previously reported [10, $29,35,36]$. High rates (91-94\%) of multiple anal HPV infections with numerous HPV genotypes ranging from 0 to 18 (mean, 4.8-5.0) were also reported in HIVpositive MSM living outside Africa, such as North Canada and Thailand $[37,38]$. In the present series, multiple anal HR-HPV infection was 5.5-times more frequent in HIV-positive than in HIV-negative MSM (univariate and multivariate analyses). Indeed, high-risk sexual behavior, including exclusive sex with other men while being HIV-infected, constitutes a significant cofactor strongly associated with increased risk of multiple anal infections with HR-HPV genotypes [39, 40]. Furthermore, MSM who are HIV-positive have an increased risk of anal HPV infection and anal cancer, and HIV infection is considered to be an independent risk factor strongly associated with an increased risk of contracting HR-HPV anal infection [40, 41]. Thus, HPV prevalence rates of $89-93 \%$ have been reported among HIV-positive MSM in a recent systematic review and meta-analysis of 53 studies [42]. The incidence of anal cancer among HIV-positive MSM is more than 80 -fold higher than that observed in the general population [43-45]. HIV infection has been shown to increase susceptibility to persistent HPV, increasing the risk of acquiring new HPV infections and reactivation of latent HPV infections [37]. Persons who are at high-risk for HIV acquisition may be at higher risk of HPV infection due to the same highrisk sexual practices [25]. Overall, our observations confirm the close and probably synergistic links between HIV infection, the high prevalence of HR-HPV anal shedding and by extension, the risk of anal cancer in MSM living in sub-Saharan Africa.

Our study had some limitations. Indeed, the recruitment of participants from only the Clinic of the National NGO Soutoura in Bamako focused on the care of key populations as well as the small sample size of our study population, may have introduced selection bias, with particularly elevated HIV prevalence of study MSM and high access to antiretroviral treatment. Thus, the study participants may be not completely representative of the MSM community of the Mali, especially regarding the 
prevalences of HIV and anal HPV, and the genotypes distribution of anal HPV. Furthermore, some risk factors may have been underestimated in the statistical analyses.

In conclusion, MSM community living in Bamako constitutes a vulnerable population at high-risk for HRHPV anal infections. MSM in Mali should urgently receive adapted STIs and anal cancer prevention, screening and care, with the implementation of innovative and adapted preventive interventions against HPV infection and associated cancers.

\begin{abstract}
Abbreviations
ACS: American Cancer Society; 95\% CI: 95\% confidence intervals; DNA: Desoxyribonucleic acid; HIV: Human Immunodeficiency virus; HPV: Human Papillomavirus; HR-HPV: High-risk Human Papillomavirus; MSM: Men who have sex with men; MSMW: Men having sex with both men and women; aOR: adjusted Odds ratios; COR: crude Odds ratios; STI: Sexually transmitted infections; WHO: World health organization.
\end{abstract}

\section{Acknowledgments}

The authors are grateful to the NGO SOUTOURA, specialized in the care of key populations, for the mobilization of MSM and the provision of its clinic for the taking of samples.

\section{Authors' Contributions}

LB: Conceptualization; DK and AM conceived and designed the research; AMA and JBB carried out the samples; RSMB carried out the experiments; DK and $A B$ performed the statistical analyzes; $L B, D K, R S M B, D V$ and HP analyzed the results and wrote the manuscript.

\section{Funding}

This research did not receive any specific grant from funding agencies in the public, commercial, or not-for-profit sectors.

\section{Availability of Data and Materials}

The datasets supporting the conclusions of this article are included within the article.

\section{Declarations}

\section{Ethics Approval and Consent to Participate}

The approval of the study was obtained from the Scientific Committee of the University of Bamako, Mali, which constitutes the national Ethics Committee. All participating MSMs were of legal age and their informed consent was obtained before each questionnaire was documented.

\section{Consent for Publication}

Not applicable.

\section{Competing Interests}

The authors report no conflicts of interest. The authors alone are responsible for the content and the writing of the paper.

\footnotetext{
Author details

${ }^{1}$ Centre Hospitalo-Universitaire Gabriel Touré, Bamako, Bamako, Mali. ${ }^{2}$ Faculté des Sciences de la Santé Humaine de N'Djamena, N'Djamena, Chad. ${ }^{3} E c o l e$ Doctorale Régionale en Infectiologie Tropicale, Franceville, Gabon. ${ }^{4}$ Laboratoire de Virologie, Hôpital Européen Georges Pompidou, Assistance Publique-Hôpitaux de Paris, and Université de Paris, Paris, France. ${ }^{5}$ Laboratoire du Centre Hospitalo-Universitaire Gabriel Touré, Bamako, Mali. ${ }^{6}$ Pierre Louis Institute of Epidemiology and Public Health (IPLESP), Sorbonne University, INSERM, Paris, France. ${ }^{7}$ Project Linkages - Family Health International, Bamako, Mali. ${ }^{8}$ Clinique Soutoura, Bamako, Mali.
}

Received: 1 February 2021 Accepted: 7 June 2021

Published online: 01 July 2021

\section{References}

1. Hartwig S, St Guily JL, Dominiak-Felden G, Alemany L, de Sanjose S. Estimation of the overall 259 burden of cancers, precancerous lesions, and genital warts attributable to 9-valent HPV vaccine 260 types in women and men in Europe. Infect Agent Cancer. 2017;12(1):19. https://doi.org/10.1186/ s13027-017-0129-6.

2. Scheurer ME, Tortolero-Luna G, Adler-Storthz K. Human papillomavirus infection: biology, epidemiology, and prevention. Int J Gynecol Cancer. 2005;15(5):727-46. https://doi.org/10.1111/j.1525-1438.2005.00246.x.

3. Parkin DM. The global burden of infection-associated cancers in the year 2002. Int J Cancer. 2006 Jun 15;118(12):3030-44. https://doi.org/10.1002/ ijc.21731.

4. Park JN, Papworth E, Kassegne S, Moukam L, Billong SC, Macauley I, et al. HIV prevalence and factors associated with HIV infection among men who have sex with men in Cameroon. J Int AIDS Soc. 2013;16(Suppl 3):18752.

5. Wirtz AL, Trapence G, Kamba D, Gama V, Chalera R, Jumbe V, et al. Geographical disparities in HIV prevalence and care among men who have sex with men in Malawi: results from a multisite cross-sectional survey. Lancet HIV. 2017 Jun;4(6):e260-9. https://doi.org/10.1016/S2352-3018(17)3 0042-5.

6. Looker KJ, Magaret AS, Turner KM, Vickerman P, Gottlieb SL, Newman LM Global estimates of prevalent and incident herpes simplex virus type 2 infections in 2012. PLoS One. 2015;10(1):e114989. https://doi.org/10.1371/ journal.pone.0114989.

7. Mboumba Bouassa RS, Prazuck T, Lethu T, Jenabian MA, Meye JF, Belec L. Cervical cancer in sub- Saharan Africa: a preventable noncommunicable disease. Expert Rev Anti-Infect Ther. 2017;15(6):613-27. https://doi.org/10.1 080/14787210.2017.1322902

8. Lee $\mathrm{CH}$, Lee $\mathrm{SH}$, Lee $\mathrm{S}$, Cho H, Kim KH, Lee JE, et al. Anal Human Papillomavirus Infection among HIV-Infected Men in Korea. PLoS One. 2016; $11(8): e 0161460$. https://doi.org/10.1371/journal.pone.0161460.

9. Parisi SG, Cruciani M, Scaggiante R, Boldrin C, Andreis S, Dal Bello F, et al. Anal and oral human papillomavirus (HPV) infection in HIV-infected subjects in northern Italy: a longitudinal cohort study among men who have sex with men. BMC Infect Dis. 2011 May 25;11(1):150. https://doi.org/10.1186/14 71-2334-11-150

10. Müller EE, Rebe K, Chirwa TF, Struthers H, Mclntyre J, Lewis DA. The prevalence of human papillomavirus infections and associated risk factors in men-who-have-sex-with-men in Cape Town. South Africa BMC Infect Dis. 2016 Aug 22;16(1):440. https://doi.org/10.1186/s12879-016-1706-9.

11. Nowak RG, Gravitt PE, He X, Ketende S, Dauda W, Omuh H, et al. Prevalence of anal high-risk human papillomavirus infections among HIV-positive and HIV-Negative Men Who Have Sex With Men in Nigeria. Sex Transm Dis. 2016 Apr:43(4):243-8. https://doi.org/10.1097/OLQ.0000000000000431.

12. Yaya I, Boyer V, Ehlan PA, Coulibaly A, Agboyibor MK, Traoré I, et al. Heterogeneity in the prevalence of high-risk human papillomavirus infection in HIV-negative and HIV-positive men who have sex with men in West Africa. Clin Infect Dis. 2021 Feb 19:ciab157.

13. Lieber M, Reynolds CW, Lieb W, McGill S, Beddoe AM. Human papillomavirus knowledge, attitudes, practices, and prevalence among men who have sex with men in Monrovia. Liberia J Low Genit Tract Dis. 2018 Oct;22(4):326-32. https://doi.org/10.1097/LGT.0000000000000436.

14. Nowak RG, Bentzen SM, Ravel J, Crowell TA, Dauda W, Ma B, et al. TRUST/ RV368 Study Group. Anal microbial patterns and oncogenic human papillomavirus in a pilot study of nigerian men who have sex with men at risk for or living with HIV. AIDS Res Hum Retrovir. 2019 Mar;35(3):267-75. https://doi.org/10.1089/aid.2018.0158.

15. Ferré VM, Gbeasor-Komlanvi FA, Collin G, Dagnra AC, Le Hingrat Q, Jaquet $A$, et al. Prevalence of human papillomavirus, human immunodeficiency virus, and other sexually transmitted infections among men who have sex with men in Togo: a national cross-sectional survey. Clin Infect Dis. 2019 Aug 30;69(6):1019-26. https://doi.org/10.1093/cid/ciy1012.

16. Hood JE, Gottlieb GS, Kiviat NB, Sow PS, Toure M, Feng Q, et al. The association between HPV, intraepithelial lesions and HIV-1 shedding in anogenital specimens in two contrasting populations: Senegalese women and American MSM. Int J STD AIDS. 2016 Apr;27(5):353-62. https://doi.org/1 $0.1177 / 0956462415580691$ 
17. Togo J, Maiga Al, Sylla M, Kone B, Dolo O, Traore FT, et al. Evaluation of two HIV rapid diagnostic tests in a context of strains' genetic diversity in Mali. AIDS Res Hum Retrovir. 2019 Feb;35(2):145-9. https://doi.org/10.1089/aid.201 7.0296.

18. Mboumba Bouassa RS, Mbeko Simaleko M, Camengo SP, Mossoro-Kpinde CD, Veyer D, Matta M, et al. Unusual and unique distribution of anal highrisk human papillomavirus (HR-HPV) among men who have sex with men living in the Central African Republic. PLoS One. 2018 May 24;13(5): e0197845. https://doi.org/10.1371/journal.pone.0197845.

19. Rindskopf D. Infinite parameter estimates in logistic regression: opportunities, not Problems. J Educ Behav Stat 2002; 27(2)147-161. https:// doi.org/10.3102/10769986027002147. Available at http://www.jstor.org/sta ble/3648130 (Last accessed 15 January 2021).

20. World Health Organization. Bureau du Mali. Rapport Annuel 2018. Available at: https://www.afro.who.int/sites/default/files/201901/OMS\%20MALI\%20Ra pport\%20annuel\%202018.pdf (Last access 18 January 2021)

21. Lahuerta M, Patnaik P, Ballo T, Telly N, Knox J, Traore B, et al. HIV prevalence and related risk factors in men who have sex with men in Bamako, Mali: findings from a bio-behavioral survey using respondent-driven sampling AIDS Behav. 2018 Jul;22(7):2079-88. https://doi.org/10.1007/s10461-017-1 793-7.

22. Telly N, Sangho O, Ballo T, Maiga M, Lahuerta M, Padmaja P, et al. Factors associated with not being tested for HIV among MSM population in Bamako. Mali J Infect Dis Epidemiol. 2020;6:170.

23. Keglovitz K, Richardson AD, Lancki N, Walsh T, Schneider JA. Anal squamous intraepithelial lesions and HPV among young black men who have sex with men. LGBT Health. 2017;4(1):72-4. https://doi.org/10.1089/lgbt.2016.0049.

24. Donà MG, Palamara G, Di Carlo A, Latini A, Vocaturo A, Benevolo $M$, et al. Prevalence, genotype diversity and determinants of anal HPV infection in HIV-uninfected men having sex with men. J Clin Virol. 2012;54(2):185-9. https://doi.org/10.1016/j.jcv.2012.02.014.

25. Hu Y, Qian HZ, Sun J, Gao L, Yin L, Li X, et al. Anal human papillomavirus infection among HIV-infected and uninfected men who have sex with men in Beijing. China J Acquir Immune Defic Syndr. 2013;64(1):103-14. https:// doi.org/10.1097/QAl.0b013e31829b6298.

26. Cranston RD, Althouse AD, van Griensven F, Janocko L, Curlin ME, Chaikummao $S$, et al. Prevalence of anal human papillomavirus vaccine types in the Bangkok men who have sex with men cohort study. Sex Transm Dis. 2015;42(12):671-6. https://doi.org/10.1097/OLQ.00000000000003 72.

27. Ren X, Ke W, Zheng H, Yang L, Huang S, Qin X, et al. Human papillomavirus positivity in the anal canal in HIV-infected and HIV-uninfected men who have anal sex with men in Guangzhou, China: implication for anal exams and early vaccination. Biomed Res Int. 2017;2017:2641259.

28. Goldstone S, Palefsky JM, Giuliano AR, Moreira ED Jr, Aranda C, Jessen H, et al. Prevalence of and risk factors for human papillomavirus (HPV) infection among HIV-seronegative men who have sex with men. J Infect Dis. 2011;203(1):66-74. https://doi.org/10.1093/infdis/jiq016.

29. Nyitray AG, Carvalho da Silva RJ, Baggio ML, Lu B, Smith D, Abrahamsen M, et al. Age-specific prevalence of and risk factors for anal human papillomavirus (HPV) among men who have sex with women and men who have sex with men: the HPV in men (HIM) study. J Infect Dis. 2011; 203(1):49-57. https://doi.org/10.1093/infdis/jiq021.

30. Forman D, de Martel C, Lacey CJ, Soerjomataram I, Lortet-Tieulent J, Bruni L, et al. Global burden of human papillomavirus and related diseases. Vaccine. 2012;30(Suppl 5):F12-23. https://doi.org/10.1016/j.vaccine.2012.07.055.

31. Saraiya M, Unger ER, Thompson TD, Lynch CF, Hernandez BY, Lyu CW, et al. HPV typing of cancers workgroup. US assessment of HPV types in cancers: implications for current and 9-valent HPV vaccines. J Natl Cancer Inst. 2015; 107(6):djv086.

32. Centers for Disease Control and Prevention (CDC). Recommendations on the use of quadrivalent human papillomavirus vaccine in males Advisory Committee on Immunization Practices (ACIP), 2011. MMWR Morb Mortal Wkly Rep. 2011 Dec 23;60(50):1705-8.

33. Petrosky E, Bocchini JA Jr, Hariri S, Chesson H, Curtis CR, Saraiya M, et al. Centers for Disease Control and Prevention (CDC). Use of 9-valent human papillomavirus (HPV) vaccine: updated HPV vaccination recommendations of the advisory committee on immunization practices. MMWR Morb Mortal Wkly Rep. 2015 Mar 27;64(11):300-4.

34. Dangerfield DT II, Smith LR, Anderson JN, Bruce OJ, Farley J, Bluthenthal R. Sexual positioning practices and sexual risk among black gay and bisexual men: a life course perspective. AIDS Behav. 2018;22(6):1919-31. https://doi. org/10.1007/s10461-017-1948-6.

35. Cranston RD, Murphy R, Weiss RE, Da Costa M, Palefsky J, Shoptaw S, et al. Anal human papillomavirus infection in a street-based sample of drug using HIV-positive men. Int J STD AIDS. 2012;23(3):195-200. https://doi.org/10.12 58/ijsa.2011.011169.

36. del Amo J, González C, Geskus RB, Torres M, Del Romero J, Viciana P, et al. What drives the number of high-risk human papillomavirus types in the anal canal in HIV-positive men who have sex with men? J Infect Dis. 2013; 207(8):1235-41. https://doi.org/10.1093/infdis/jit028.

37. de Pokomandy A, Rouleau D, Ghattas G, Vezina S, Cote P, Macleod J, et al Prevalence, clearance, and incidence of anal human papillomavirus infection in HIV-infected men: the HIPVIRG cohort study. J Infect Dis. 2009;199(7):96573. https://doi.org/10.1086/597207.

38. Supindham $T$, Chariyalertsak $S$, Utaipat U, Miura T, Ruanpeng $D$, Chotirosniramit $\mathrm{N}$, et al. High prevalence and genotype diversity of anal HPV infection among MSM in Northern Thailand. PLoS One. 2015;10(5): e0124499. https://doi.org/10.1371/journal.pone.0124499.

39. Méndez-Martínez R, Rivera-Martínez NE, Crabtree-Ramírez B, Sierra-Madero JG, Caro-Vega Y, Galván SC, et al. Multiple human papillomavirus infections are highly prevalent in the anal canal of human immunodeficiency viruspositive men who have sex with men. BMC Infect Dis. 2014;14(1):671. https://doi.org/10.1186/s12879-014-0671-4.

40. Ong JJ, Chen M, Tabrizi SN, Cornall A, Garland SM, Jin F, et al. Anal HPV detection in men who have sex with men living with HIV who report no recent anal sexual behaviours: baseline analysis of the Anal Cancer Examination (ACE) study. Sex Transm Infect. 2016;92(5):368-70. https://doi. org/10.1136/sextrans-2015-052121.

41. Baggaley RF, White RG, Boily MC. HIV transmission risk through anal intercourse: systematic review, meta-analysis and implications for HIV prevention. Int J Epidemiol. 2010 Aug;39(4):1048-63. https://doi.org/10.1093/ ije/dyq057.

42. Machalek DA, Poynten M, Jin F, Fairley CK, Farnsworth A, Garland SM, et al. Anal human papillomavirus infection and associated neoplastic lesions in men who have sex with men: a systematic review and meta-analysis. Lancet Oncol. 2012;13(5):487-500. https://doi.org/10.1016/S1470-2045(12 )70080-3.

43. Chaturvedi AK, Madeleine MM, Biggar RJ, Engels EA. Risk of human papillomavirus-associated cancers among persons with AIDS. J Natl Cancer Inst. 2009 Aug 19;101(16):1120-30. https://doi.org/10.1093/jnci/djp205.

44. Silverberg MJ, Lau B, Justice AC, Engels E, Gill MJ, Goedert JJ, et al. North American AIDS cohort collaboration on research and design (NA-ACCORD) of leDEA. Risk of anal cancer in HIV-infected and HIV-uninfected individuals in North America. Clin Infect Dis. 2012;54(7):1026-34. https://doi.org/10.1 093/cid/cir1012.

45. Garbuglia AR, Gentile M, Del Nonno F, Lorenzini P, Lapa D, Lupi F, et al. An anal cancer screening program for MSM in Italy: Prevalence of multiple HPV types and vaccine-targeted infections. J Clin Virol. 2015 Nov;72:49-54. https://doi.org/10.1016/j.jcv.2015.09.001

\section{Publisher's Note}

Springer Nature remains neutral with regard to jurisdictional claims in published maps and institutional affiliations.

Ready to submit your research? Choose BMC and benefit from:

- fast, convenient online submission

- thorough peer review by experienced researchers in your field

- rapid publication on acceptance

- support for research data, including large and complex data types

- gold Open Access which fosters wider collaboration and increased citations

- maximum visibility for your research: over $100 \mathrm{M}$ website views per year

At $\mathrm{BMC}$, research is always in progress.

Learn more biomedcentral.com/submission 